\title{
Serum albumin levels as a predictive biomarker for low-load resistance training programs' effects on muscle thickness in the community-dwelling elderly Japanese population: interventional study result
}

\author{
Shuji Sawada', Hayao Ozaki ${ }^{2,3}$, Toshiharu Natsume ${ }^{1,4}$, Daiki Nakano ${ }^{5,6}$, Pengyu Deng ${ }^{2,6}$, Toshinori Yoshihara ${ }^{2,6}$,
} Takuya Osawa ${ }^{1,7}$, Hiroyuki Kobayashi ${ }^{8}$, Shuichi Machida ${ }^{1,2,6,9^{*}}$ and Hisashi Naito 1,2,6,9

\begin{abstract}
Background: Resistance training has been recommended as an effective measure against age-related loss of muscle mass and muscle strength, called sarcopenia, even in older adults. However, despite subjecting each participant to the same training program, the training effect solely depended on the individual. This study aimed to evaluate whether certain blood parameters influenced the effect of a low-load resistance training program on muscle thickness in the community-dwelling elderly population.

Methods: Sixty-nine community-dwelling Japanese (49 women and 20 men) subjects aged $69.4 \pm 6.5$ years were included. Low-load resistance training was performed twice a week for 12 weeks. Muscle thickness at the anterior aspects of the thigh (AT) was measured using a B-mode ultrasound device, and 22 blood parameter levels were assessed before and after the program. We checked the first quartile value of each parameter to establish cutoff values, and participants were divided into low or normal groups for each parameter.
\end{abstract}

Results: A low-load resistance training program significantly increased muscle thickness at the AT. The interaction between time and groups was examined at low $(<4.1 \mathrm{~g} / \mathrm{dL})$ versus normal $(\geq 4.1 \mathrm{~g} / \mathrm{dL})$ serum albumin (Alb) levels. Although there was no difference in muscle thickness at the AT before the training intervention, the hypertrophic effects were higher in the normal serum Alb level group than in the low serum Alb level group. The binomial logistic regression analysis showed that participants in the low serum Alb group had an odds ratio of 7.08 for decreased muscle thickness at the AT. The effect of a low-load resistance training program on lower limb muscle thickness appears to be limited in participants with low serum Alb levels before training interventions.

Conclusions: Serum Alb level may act as a biomarker to predict the effects of low-load resistance training programs on muscle hypertrophy in elderly individuals.

\footnotetext{
* Correspondence: machidas@juntendo.ac.jp

${ }^{1}$ COI Project Center, Juntendo University, 2-1-1 Hongo, Bunkyo-ku, Tokyo

113-8421, Japan

${ }^{2}$ School of Health and Sports Science, Juntendo University, 1-1

Hirakagakuendai, Inzai, Chiba 270-1695, Japan

Full list of author information is available at the end of the article
}

C C The Author(s). 2021 Open Access This article is licensed under a Creative Commons Attribution 4.0 International License, which permits use, sharing, adaptation, distribution and reproduction in any medium or format, as long as you give appropriate credit to the original author(s) and the source, provide a link to the Creative Commons licence, and indicate if changes were made. The images or other third party material in this article are included in the article's Creative Commons licence, unless indicated otherwise in a credit line to the material. If material is not included in the article's Creative Commons licence and your intended use is not permitted by statutory regulation or exceeds the permitted use, you will need to obtain permission directly from the copyright holder. To view a copy of this licence, visit http://creativecommons.org/licenses/by/4.0/. The Creative Commons Public Domain Dedication waiver (http://creativecommons.org/publicdomain/zero/1.0/) applies to the data made available in this article, unless otherwise stated in a credit line to the data. 
Trial registration: This study was retrospectively registered in UMIN-Clinical Trial Registry (CTR), ID: UMIN000042759 (date of registration, 14 Dec 2020).

Keywords: Aged, Resistance training, Serum albumin, Muscle hypertrophy

\section{Background}

Skeletal muscle plays an important role in physical functions related to the activities of daily living [1] and in systemic energy regulation controlled by glucose and lipid metabolism [2]. Despite playing a major role in systemic homeostasis, skeletal muscle size and strength both decrease with age $[3,4]$. This age-related loss of muscle mass and muscle strength, called sarcopenia, is related to a wide range of chronic disorders [5-8], motor disorders $[9,10]$, and mortality [11]. Because of this, sarcopenia is a primary therapeutic target for improving the effects of aging in the elderly, and it has been reported that exercise intervention, especially involving resistance training, is a key approach for preventing and improving sarcopenia $[12,13]$.

Resistance training has been recommended as an effective method against the problems indicated above, even in older adults $[14,15]$. Although high-load resistance training is the primary method to reduce the effects of aging, this type of training generally requires high external loads, which may be difficult for older adults to conduct safely. To identify an appropriate approach for older adults, we found that a low-load resistance training program could induce muscle hypertrophy in middleaged and older adults [16]. However, despite subjecting each participant to the same training program, the training effect solely depended on the individual. In a previous study, it was reported that calorie restriction accelerated the catabolism of the lean body mass [17], and the effect of resistance exercise was significantly greater in the exercise and nutrition intervention group than in the exercise only group [18]. Therefore, the participants with malnutrition could only show limited training effect, and we hypothesized that we could assess this risk using blood parameters.

It is well known that blood parameters are effective screening tools for identifying the risk of metabolic syndromes, locomotive syndromes, and other multifactorial diseases [19-21]. To diagnose diseases early, annual medical checkups that include complete blood counts and blood biochemistry panels have been conducted in Japan. The consultation rate of annual medical checkups was reported to be $63.7 \%$ [22], which indicates the percentage of Japanese citizens managing their health through annual checkups. From this viewpoint, we focused on blood parameters, including complete blood counts and blood biochemistry panels, and hypothesized that these blood parameters might affect skeletal muscle adaptation in response to a low-load resistance training program. To test this, we first comprehensively verified the blood parameters, including complete blood count and blood biochemistry, which entailed annual medical checkups conducted in Japan, before and after a low-load resistance training program. Should an evidence of a relationship between the status of these blood parameters and the effect of a low-load resistance training program be revealed, several parameters could then be used as biomarkers to predict the effects of low-load resistance training programs on muscle hypertrophy in elderly individuals.

This study aimed to evaluate whether the levels of some blood parameters influenced the effect of a lowload resistance training program on lower limb muscle thickness in community-dwelling middle-aged and elderly individuals.

\section{Methods \\ Participants}

Community-dwelling middle-aged and elderly Japanese were recruited to participate in this study through printed advertisements in a public information magazine. They were informed about the methods, procedures, and risks and provided written informed consent before participating. We excluded individuals who did not follow our instructions or those with medical conditions that could limit their ability to participate in the resistance training program, based on the decision of the physician in charge. Sixty-nine participants aged $69.4 \pm$ 6.5 years (49 women and 20 men) volunteered for this study. Although 19, 16, 6, and 4 participants had a medical history of hypertension, dyslipidemia, heart failure, and diabetes mellitus, respectively, and accordingly, some of them were using medications including atorvastatin and amlodipine, they were all approved to participate in the exercise program by the physician in charge. Their heights, weights, muscle thicknesses, and blood parameters were evaluated before (pre) and after (post) the training period. This study was conducted in accordance with the Declaration of Helsinki and was approved by the Ethics Committee for Human Experiments of Juntendo University, Chiba, Japan (Approval Number: 27-52). This study was registered in UMIN-Clinical 
Trial Registry (CTR) (ID: UMIN000042759, Date of registration: December 14, 2020).

\section{Training program}

Participants were instructed to engage in a low-load resistance training program using their own body weight and an elastic band. They were also instructed to avoid changing their dietary patterns throughout the training period. The program was conducted twice a week for 12 weeks, and the total number of classes was 22 or 23 . The program was composed of nine exercises: squats, split squats, push-ups, heel raises, crunches, hip lifts, seated rows, shoulder presses, and arm curls. The first 6 exercises involved the participant's own body weight, and the last three exercises required an elastic band (Thera-Band ${ }^{\circ}$; The Hygenic Corporation, Akron, OH, USA). In the first 2 weeks of the training period, the program was composed of only 4 exercises: squats, push-ups, crunches, and hip lifts, and the participants performed 3 sets of 8 repetitions with a 60-s rest between each set. In each repetition, they were instructed to spend $3 \mathrm{~s}$ in both the concentric and eccentric phases. After the first 2 weeks, the number of exercises per session, repetitions, sets per exercise, and exercise times were gradually increased, and the rest interval was gradually decreased every 2 weeks throughout the 12-week training period. For each session, it was indicated to the participants to continue until muscle fatigue. This training program was conducted according to the protocol followed in a previous study, and the details are described by Ozaki et al. [16].

\section{Muscle thickness}

Each participant's muscle thickness was measured with a B-mode ultrasound device using a 5 to $18-\mathrm{MHz}$ scanning head (Noblus; Aloka, Tokyo, Japan). We evaluated the anterior aspects of the thigh (AT) at the midpoint between the greater trochanter and lateral condyle of the femur. The participants were required to rest in the sitting position for at least $30 \mathrm{~min}$ before the measurement and to be in a supine position during the measurement. All the measurements were performed by the same operator. Before the study, we conducted preliminary examination to check the reproducibility and calculated the test-retest (inter-session) reliability using intraclass correlation coefficient (ICC), standard errors of measurement (SEM), and minimal difference. The ICC, SEM, and minimal difference for the muscle thickness in the AT was determined in 10 older men and women as follows: $0.992,0.37 \mathrm{~mm}, 1.03 \mathrm{~mm}$, respectively. This measurement was also conducted according to the method used in a previous study, and the details are described by Ozaki et al. [16].

\section{Blood parameters}

Venous blood samples of approximately $13 \mathrm{~mL}$ were obtained following at least $2 \mathrm{~h}$ of fasting before (pre) and after (post) the 12-week training program, and the levels of the following blood parameters were assessed: white blood cell count (WBC), red blood cell count (RBC), hemoglobin $(\mathrm{Hb})$, hematocrit $(\mathrm{Ht})$, mean corpuscular volume $(\mathrm{MCV})$, mean corpuscular hemoglobin $(\mathrm{MCH})$, mean corpuscular hemoglobin concentration (MCHC), platelet count (PLT), total protein (TP), albumin (Alb), aspartate aminotransferase (glutamic oxaloacetic transaminase; AST [GOT]), alanine aminotransferase (glutamic pyruvic transaminase; ALT [GPT]), alkaline phosphatase (ALP), leucine aminopeptidase (LAP), lactate dehydrogenase (LD [LDH]), $\gamma$-glutamyl transferase ( $\gamma$-GTP), triglycerides (TG), total cholesterol (TC), highdensity lipoprotein cholesterol (HDL-C), low-density lipoprotein cholesterol (LDL-C), hemoglobin A1c (HbA1c), and fasting blood sugar (FBS). These items were monitored using the complete blood count and blood biochemistry tests, which are included in annual medical checkups conducted in Japan.

We checked each blood parameter's first quartile value before (pre) the training program, to establish the following cutoff criteria for the reduced levels: $\mathrm{WBC}=4400 / \mu \mathrm{L}, \mathrm{RBC}=414 \times 10^{4} / \mu \mathrm{L}, \mathrm{Hb}=12.6 \mathrm{~g} / \mathrm{dL}$, $\mathrm{Ht}=37.9 \%, \mathrm{MCV}=87.7 \mathrm{fL}, \mathrm{MCH}=29.2 \mathrm{pg}, \mathrm{MCHC}=$ $32.8 \%, \quad \mathrm{PLT}=18.8 \times 10^{4} / \mu \mathrm{L}, \mathrm{TP}=7 \mathrm{~g} / \mathrm{dL}, \quad \mathrm{Alb}=4.1 \mathrm{~g} /$ $\mathrm{dL}, \operatorname{AST}(\mathrm{GOT})=18 \mathrm{U} / \mathrm{L}, \mathrm{ALT}(\mathrm{GPT})=14 \mathrm{U} / \mathrm{L}, \mathrm{ALP}=$ $178 \mathrm{U} / \mathrm{L}, \quad \mathrm{LAP}=45 \mathrm{U} / \mathrm{L}, \quad \mathrm{LD}(\mathrm{LDH})=169 \mathrm{U} / \mathrm{L}, \quad \gamma$ $\mathrm{GTP}=14 \mathrm{U} / \mathrm{L}, \mathrm{TC}=181 \mathrm{mg} / \mathrm{dL}, \mathrm{HDL}-\mathrm{C}=52 \mathrm{mg} / \mathrm{dL}$, $\mathrm{TG}=85 \mathrm{mg} / \mathrm{dL}, \mathrm{LDL}-\mathrm{C}=102 \mathrm{mg} / \mathrm{dL}, \mathrm{HbA} 1 \mathrm{c}=5.3 \%$, and $\mathrm{FBS}=95 \mathrm{mg} / \mathrm{dL}$. Using criteria for each blood parameter, participants were divided into the first quartile group, which is the lowest quartile group, as participants in this group have relatively low blood parameter values, or into the combined second, third, and fourth quartile groups with participants having normal blood parameter values.

\section{Statistical analyses}

To verify the training effect on muscle thickness at the AT, we analyzed the parameters before (pre) and after (post) the training program. Data were analyzed using the paired t-tests, two-way analysis of variance, analysis of covariance, and binomial logistic regression analysis. When there was a significant interaction in the two-way analysis of variance between time and group, the simple main effects analysis was conducted. In the binomial logistic regression analysis, we included age and sex as confounding factors, and the variable selection was conducted using a stepwise method with $p=0.20 . P$ less than 0.05 was considered statistically significant. Results were expressed as means and standard deviations, and 
the odds ratio was represented by means and $95 \%$ confidence intervals. Statistical analyses were performed using BellCurve for Excel (Social Survey Research Information Co., Ltd., Japan).

\section{Results}

The participants' average height was $156.8 \pm 7.6 \mathrm{~cm}$, and the average weight was $59.1 \pm 10.3 \mathrm{~kg}$. The average participation rate of the classes was $87.4 \%$ (range: 63.6$100.0 \%$ ). Of the 69 participants, 4 had smoking habit, 12 drank alcohol every day, and 24 drank alcohol sometimes.

The average muscle thickness at the AT of all participants was $26.65 \pm 5.12 \mathrm{~mm}$ before the training intervention, which significantly increased to $29.48 \pm 5.38 \mathrm{~mm}$ after undergoing the biweekly low-load resistance training program for 12 weeks $(p<0.001$, Fig. 1a). The average serum Alb concentration of all participants was $4.25 \pm 0.25 \mathrm{~g} / \mathrm{dL}$ before the training intervention, which significantly increased to $4.32 \pm 0.26 \mathrm{~g} / \mathrm{dL}$ after the training program $(p<0.001$, Fig. $1 \mathrm{~b})$.

Using the blood parameter criteria, we checked the first quartile value of each blood parameter to establish the cutoff criteria for reduced levels (Table 1). When the two-way analysis of variance was conducted, the effects were significant for time, but not for group, and the time $\times$ group interactions were significant for low $(<32.8 \%)$ versus normal $(\geq 32.8 \%) \mathrm{MCHC}$, low $(<4.1 \mathrm{~g} / \mathrm{dL})$ versus normal $(\geq 4.1 \mathrm{~g} / \mathrm{dL})$ serum Alb levels, and low $(<$ $102 \mathrm{mg} / \mathrm{dL}$ ) versus normal ( $\geq 102 \mathrm{mg} / \mathrm{dL})$ serum LDL-C levels $(p<0.05$; Table 2). When comparing the low and normal serum Alb level groups using the simple main effects analysis, muscle thickness at the AT was only significantly increased in the normal serum Alb level group (pre: $26.96 \pm 5.13 \mathrm{~mm}$, post: $30.26 \pm 5.31 \mathrm{~mm}, p<$ 0.001; Fig. 2a). Additionally, there was no difference in muscle thickness at the AT before the training intervention; however, participants in the normal serum Alb level group had greater muscle thickness after the training intervention than those in the low serum Alb level group (low: $26.45 \pm 4.68 \mathrm{~mm}$, normal: $30.26 \pm 5.31 \mathrm{~mm}$, $p<0.001$; Fig. 2a). To verify the effect of participation rate of the classes on serum Alb level and muscle thickness at the AT, an analysis of covariance was conducted. Although regression parallelism was confirmed, the regression was not significant. Time $\times$ group interactions were also detected in the MCHC and serum LDL-C levels $(p<0.001$; Table 2$)$. When comparing the low and normal MCHC groups using the simple main effects analysis, muscle thickness at the AT were significantly increased both in the low MCHC group (pre: $25.05 \pm$ $5.82 \mathrm{~mm}$, post: $29.45 \pm 4.83 \mathrm{~mm}, p<0.001$; Fig. $2 \mathrm{~b}$ ) and the normal MCHC group (pre: $27.02 \pm 4.93 \mathrm{~mm}$, post: $29.49 \pm 5.54 \mathrm{~mm}, p<0.001$; Fig. $2 \mathrm{~b}$ ); however, the increase was greater in the low $\mathrm{MCHC}$ group. On the other hand, when comparing the low and normal $\mathrm{MCHC}$ groups using the simple main effects analysis, muscle thickness at the AT was significantly increased both in the low serum LDL-C level group (pre: $27.22 \pm$ $5.77 \mathrm{~mm}$, post: $28.67 \pm 5.63 \mathrm{~mm}, p<0.05$; Fig. $2 \mathrm{c}$ ) and the normal serum LDL-C level group (pre: $26.46 \pm 4.94$ $\mathrm{mm}$, post: $29.75 \pm 5.32 \mathrm{~mm}, p<0.001$; Fig. $2 \mathrm{c}$ ); however, the increase was greater in the normal serum LDL-C level group.

To verify the influence that serum Alb concentration and serum Alb levels $(<4.1 \mathrm{~g} / \mathrm{dL}$ or not $)$ had on the (a)

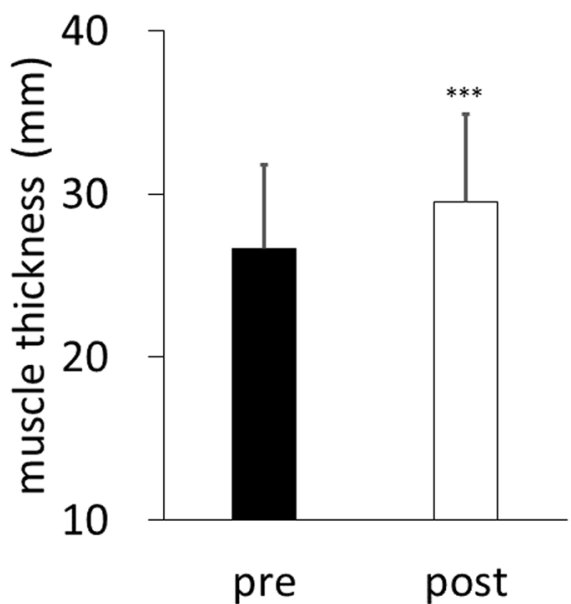

(b)

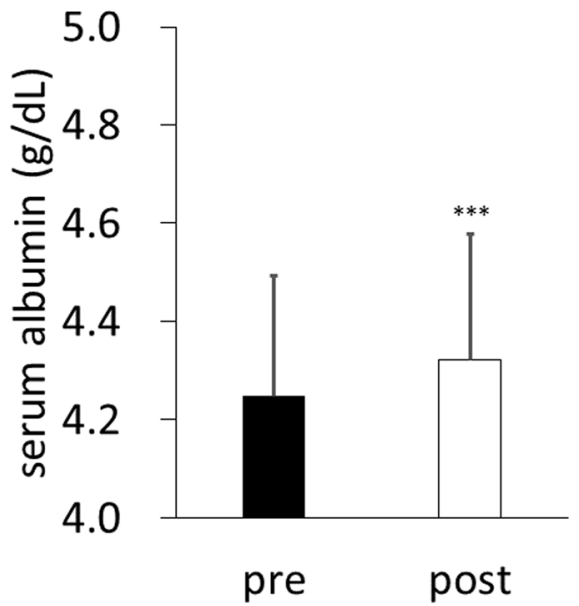

Fig. 1 Effect of a low-load resistance training program on (a) muscle thickness, and (b) serum albumin levels. Data are presented as mean \pm standard deviation (SD). $N=69$ 
Table 1 The first quartile value of each blood parameter

\begin{tabular}{|c|c|c|c|c|c|c|c|}
\hline & Unit & Mean Value & Minimum Value & Maximum Value & Median Value & $1^{\text {st }}$ Quartile Value & Interquartile Range \\
\hline$\overline{W B C}$ & $/ \mu \mathrm{L}$ & 5369.6 & 2800 & 8400 & 5300 & 4400 & 1900 \\
\hline RBC & $\times 10^{4} / \mu \mathrm{L}$ & 439.7 & 366 & 552 & 435 & 414 & 49 \\
\hline $\mathrm{Hb}$ & $\mathrm{g} / \mathrm{dL}$ & 13.2 & 10.3 & 16.2 & 13.2 & 12.6 & 1.2 \\
\hline $\mathrm{Ht}$ & $\%$ & 39.64 & 32.8 & 48 & 39.6 & 37.9 & 3.3 \\
\hline MCV & $\mathrm{fL}$ & 90.35 & 77.5 & 101 & 89.9 & 87.7 & 5.5 \\
\hline $\mathrm{MCH}$ & $\mathrm{pg}$ & 30.09 & 25.5 & 33.5 & 30.1 & 29.2 & 1.9 \\
\hline $\mathrm{MCHC}$ & $\%$ & 33.3 & 30.9 & 34.7 & 33.2 & 32.8 & 1.0 \\
\hline PLT & $\times 10^{4} / \mu \mathrm{L}$ & 22.78 & 13.2 & 47.1 & 21.5 & 18.8 & 6.7 \\
\hline TP & $\mathrm{g} / \mathrm{dL}$ & 7.23 & 6.6 & 8 & 7.2 & 7 & 0.5 \\
\hline Alb & $\mathrm{g} / \mathrm{dL}$ & 4.25 & 3.7 & 4.9 & 4.2 & 4.1 & 0.3 \\
\hline AST(GOT) & $U / L$ & 21.6 & 12 & 41 & 21 & 18 & 5 \\
\hline $\mathrm{ALT}(\mathrm{GPT})$ & $U / L$ & 19.4 & 7 & 63 & 16 & 14 & 7 \\
\hline ALP & $U / L$ & 216.7 & 74 & 387 & 211 & 178 & 68 \\
\hline LAP & $\mathrm{U} / \mathrm{L}$ & 48.2 & 32 & 83 & 47 & 45 & 5 \\
\hline $\mathrm{LD}(\mathrm{LDH})$ & $U / L$ & 190.9 & 135 & 276 & 189 & 169 & 43 \\
\hline$\gamma$-GTP & $\mathrm{U} / \mathrm{L}$ & 23.4 & 10 & 107 & 20 & 14 & 13 \\
\hline TG & $\mathrm{mg} / \mathrm{dL}$ & 140.7 & 46 & 393 & 132 & 85 & 86 \\
\hline TC & $\mathrm{mg} / \mathrm{dL}$ & 209.7 & 148 & 307 & 209 & 181 & 48 \\
\hline $\mathrm{HDL}-\mathrm{C}$ & $\mathrm{mg} / \mathrm{dL}$ & 62.2 & 29 & 101 & 60 & 52 & 20 \\
\hline LDL-C & $\mathrm{mg} / \mathrm{dL}$ & 121.2 & 64 & 211 & 114 & 102 & 36 \\
\hline $\mathrm{HbA1c}$ & $\%$ & 5.57 & 4.7 & 7.3 & 5.5 & 5.3 & 0.4 \\
\hline FBS & $\mathrm{mg} / \mathrm{dL}$ & 106.6 & 72 & 191 & 102 & 95 & 16 \\
\hline
\end{tabular}

WBC white blood cell count, $R B C$ red blood cell count, $H b$ hemoglobin, $H$ t hematocrit, $M C V$ mean corpuscular volume, $M C H$ mean corpuscular hemoglobin, $M C H C$ mean corpuscular hemoglobin concentration, PLT platelet count, TP total protein, Alb albumin, AST(GOT) aspartate aminotransferase (glutamic oxaloacetic transaminase), $A L T(G P T)$ alanine aminotransferase (glutamic pyruvic transaminase), $A L P$ alkaline phosphatase, $L A P$ leucine aminopeptidase, $L D(L D H)$ lactate dehydrogenase, $\gamma$-GTP $\gamma$-glutamyltransferase, TG triglyceride, $T C$ total cholesterol, $H D L-C$ high-density lipoprotein cholesterol, $L D L-C$ low-density lipoprotein cholesterol, HbA1c hemoglobin A1c, FBS fasting blood sugar

change in muscle thickness at the AT, binomial logistic regression analysis was performed with muscle thickness at the AT (increased as 0 , decreased as 1) as a target variable and age, sex, serum Alb concentration, and serum Alb level $(\geq 4.1 \mathrm{~g} / \mathrm{dL}$ as $0,<4.1 \mathrm{~g} / \mathrm{dL}$ as 1$)$ as explanatory variables. The serum Alb level was selected as a significant variable $(p=0.0102)$, and the odds ratio for decreasing muscle thickness at the AT was 7.08, while the $95 \%$ confidence interval was $1.59-31.54$.

\section{Discussion}

This study revealed that a low-load resistance training program using a participant's own body weight and elastic bands, even when performed only twice a week, induced muscle hypertrophy after 12 weeks of training intervention in community-dwelling elderly Japanese participants. The average muscle thickness at the AT increased by about $10 \%$ over the 12 weeks of the low-load resistance training program. However, there were individual differences in the training effect on muscle thickness at the AT. For example, the increase was restricted in individuals with a relatively lower serum Alb before the training intervention. We first comprehensively verified the blood parameters that were included in the annual medical checkups conducted in Japan before and after the low-load resistance training program. Our data newly suggested that low serum Alb levels may predict decreased efficacy of a low-load resistance training intervention on muscle thickness in community-dwelling elderly Japanese participants. Hence, this may be a predictive biomarker for the effect of a low-load resistance training program on muscle hypertrophy.

It is common to divide participants using quartile values of blood parameters or based on physical performance tests $[23,24]$; here, we compared the lowest quartile with the three higher quartiles combined as reported in a previous study [25]. When we divided the participants into two groups using each blood parameter's quartile criteria (Table 1), an interaction between time and group was detected for $\mathrm{MCHC}$, serum $\mathrm{Alb}$ levels, and serum LDL-C levels (Table 2). The training effect on muscle thickness at the AT was limited in the 
Table 2 Summarized results of the two-way analysis of variance

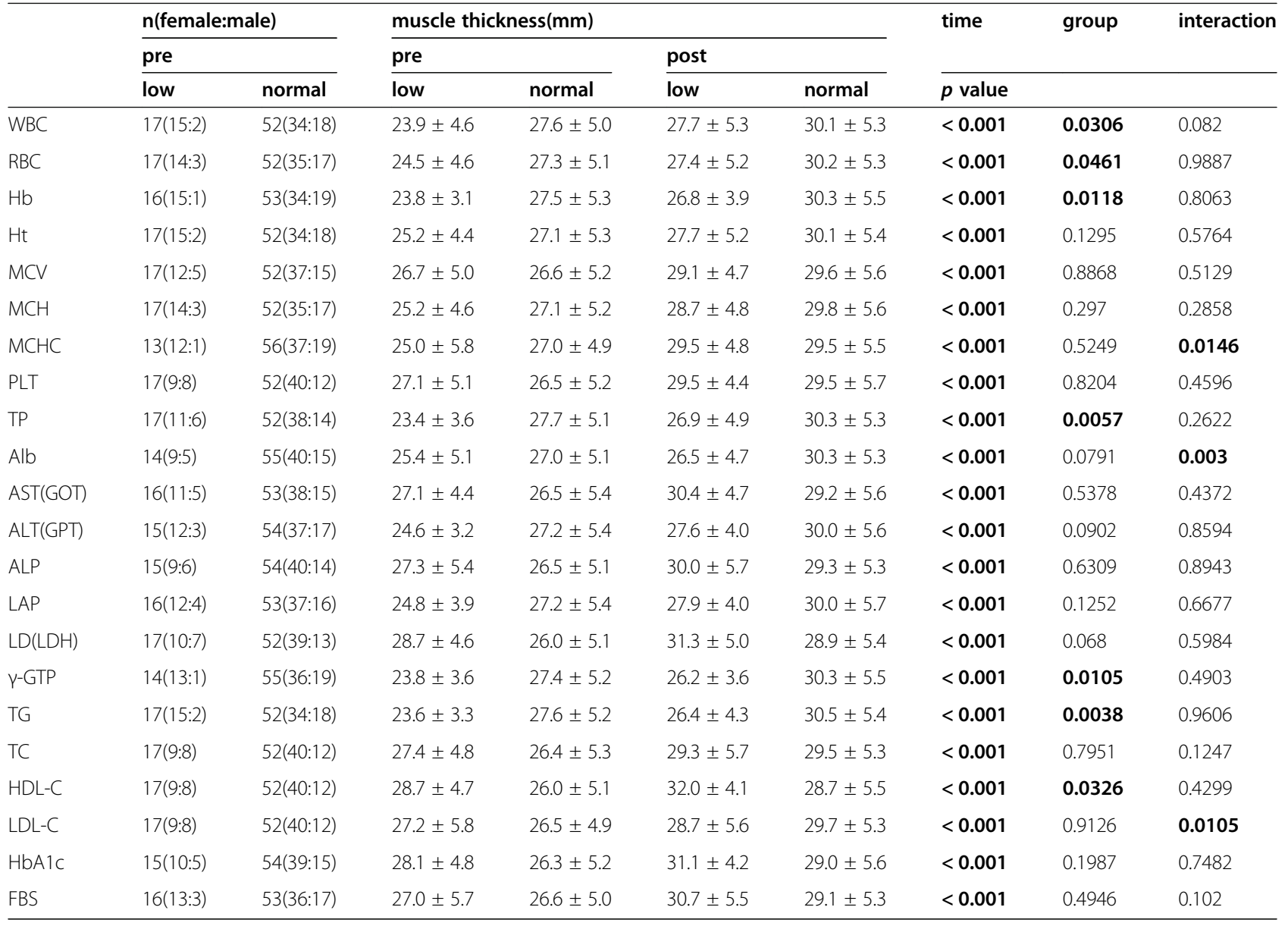

Data of muscle thickness are presented as mean \pm SD

WBC white blood cell count, $R B C$ red blood cell count, $H b$ hemoglobin, $H t$ hematocrit, $M C V$ mean corpuscular volume, $M C H$ mean corpuscular hemoglobin, $M C H C$ mean corpuscular hemoglobin concentration, PLT platelet count, TP total protein, Alb albumin, AST(GOT) aspartate aminotransferase (glutamic oxaloacetic transaminase), $A L T(G P T)$ alanine aminotransferase (glutamic pyruvic transaminase), $A L P$ alkaline phosphatase, $L A P$ leucine aminopeptidase, $L D(L D H)$ lactate dehydrogenase, $\gamma$-GTP $\gamma$-glutamyltransferase, TG triglyceride, $T C$ total cholesterol, HDL-C high-density lipoprotein cholesterol, $L D L-C$ low-density lipoprotein cholesterol, HbA1c hemoglobin A1c, FBS fasting blood sugar

low serum Alb group compared with that in the normal serum Alb group (Fig. 2a). However, this result was neither confirmed in the low $\mathrm{MCHC}$ group compared with that in the normal MCHC group (Fig. 2b) nor in the low serum LDL-C group compared with that in the normal serum LDL-C group (Fig. 2c). From the results of the analysis of covariance, this was not affected by the participation rate of the classes. We also showed that the effect of low serum Alb level on muscle thickness at the AT was not affected by age and sex because these parameters were not selected as variables in the binomial logistic regression analysis. The results of the binomial logistic regression analysis showed that classification in the low serum Alb group had an odds ratio of 7.08 for decreasing muscle thickness at the AT, which supports the above-mentioned limitation. Although this criterion was much higher than that of clinical malnutrition $(<$ $3.5 \mathrm{~g} / \mathrm{dL}$ ), the patients with relatively low serum Alb had inhibited training effects. This influence was not seen in participants with lower levels of the other blood parameters, including $\mathrm{MCHC}$ and LDL-C (Table 2; Fig. 2b, and Fig. 2c). Our data demonstrated that the effect of a lowload resistance training program on lower limb muscle thickness appears to be limited in participants, depending on their serum Alb levels before the training intervention. Serum Alb is a clinical indicator of energy and protein deficiency; therefore, our data suggest that participants with lower serum Alb before a training intervention ought to improve their nutritional status to obtain the most optimal training effects on their muscle mass. The relatively lower serum Alb level (3.9-4.2 g/ $\mathrm{dL})$ was also reported to be related to cognitive decline or dementia [26-28]. Some other previous longitudinal observational studies reported that relatively lower serum Alb levels were associated with loss of muscle mass and muscle strength $[24,29,30]$. It was also 

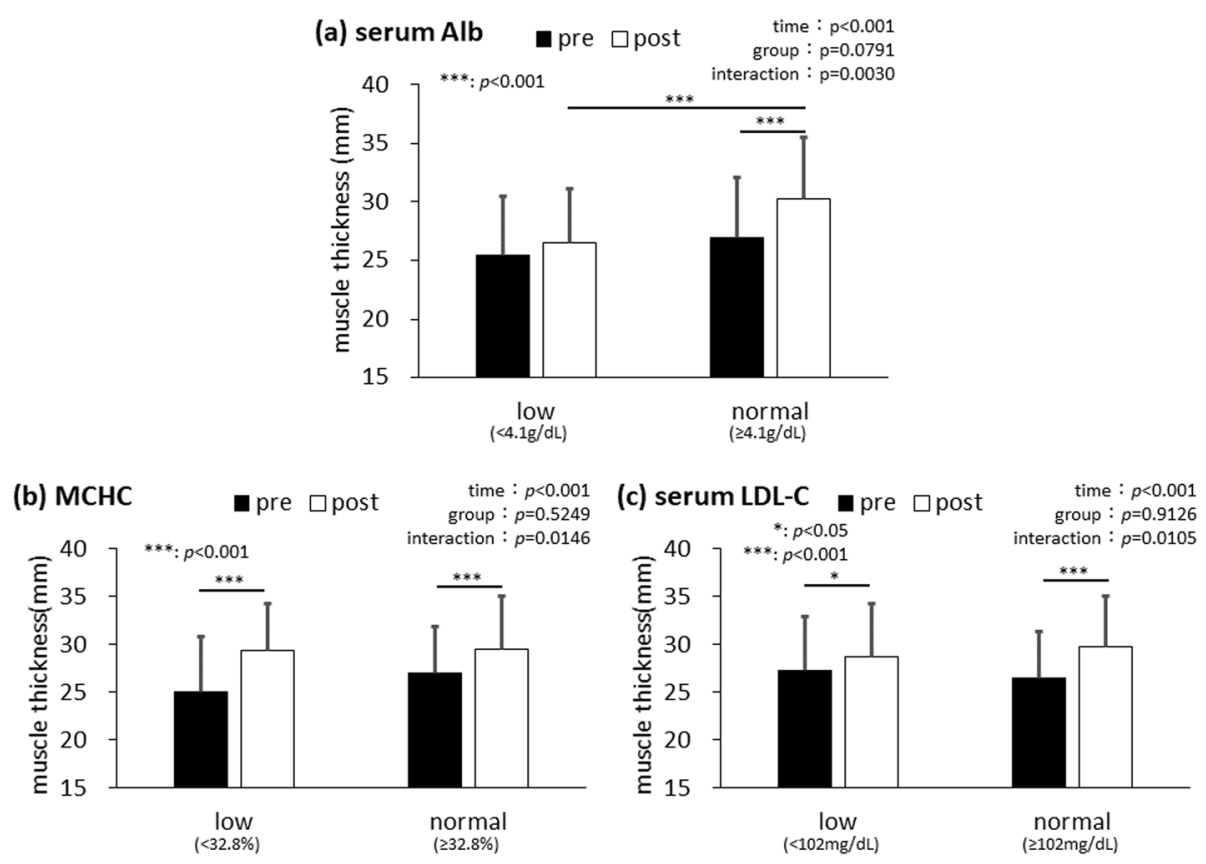

Fig. 2 Comparison of changes in muscle thickness for (a) low and normal serum albumin (Alb) levels, b low and normal mean corpuscular hemoglobin concentration (MCHC), and c low serum and normal low-density lipoprotein-cholesterol (LDL-C) levels. Data were analyzed using two-way analysis of variance; the main effects on time, but not on group, and the time $\times$ group interactions were significant for all three measurements. Although the time $\times$ group interactions were detected in all three measurements, a significant difference after training intervention was only detected in serum Alb levels compared with the low and normal groups using Tukey's multiple comparison test as a post-hoc analysis. Data are presented as mean \pm standard deviation (SD). N=69

reported that a relatively lower serum Alb level combined with sarcopenia would increase disability risk in older adults [31]. As these studies and our data showed, even though the serum Alb level is much higher than that of clinical malnutrition $(<3.5 \mathrm{~g} / \mathrm{dL})$, relatively lower serum Alb level might be an indicator for our healthy aging. $\mathrm{MCHC}$ is one of the indexes for evaluating anemia, whereas serum LDL-C is one of the indexes for evaluating dyslipidemia. Although these two parameters might also reflect the nutritional status, only serum Alb had an effect of the low-load resistance training program on the lower limb muscle thickness. The relatively lower criteria that were not within clinically abnormal range, were similar for these three parameters. Therefore, serum Alb might detect a poor physical condition in the early stages.

Measuring the muscle thickness via a B-mode ultrasound device is a non-invasive method for assessing the muscle mass, which can also be assessed individually. The training effects tend to occur in site-specific manner; thus, this method is useful for assessing the training effects on muscle mass. Some RCTs in older adults revealed that exercise intervention improved muscle mass when assessed by dual energy $\mathrm{X}$-ray absorptiometry [32] or segmental multifrequency bioelectrical impedance analysis [33]. Our data is important because it revealed that a low-load resistance training program is effective at increasing the site-specific muscle mass in community-dwelling middle-aged and older adults.

Our study had some limitations. First, we did not include a control group when we verified the effects of the 12-week training intervention, and we also did not conduct the reproducibility measures in these participants. Second, even though it has been reported that a combination of exercise and a nutritional approach is the most effective method to improve sarcopenia, we did not control for the participants' nutrient intake during the training period. Third, although there were $71 \%$ female participants included, we could not verify the sex difference when examining the association between serum Alb levels and the low-load resistance training effects. Fourth, the sample size of 69 was small. Fifth, although it was approved that all the participants join the exercise program by the physician in charge, their medical history or their use of oral medications might have affected the blood parameters, which we assessed in this study. To minimize these limitations, further studies must be conducted in the future.

\section{Conclusions}

In conclusion, serum Alb levels may be a predictive biomarker for the effect of a low-load resistance training 


\section{program on muscle hypertrophy in community-dwelling elderly individuals.}

\section{Abbreviations}

AT: The anterior aspects of the thigh; WBC: White blood cell count; RBC: Red blood cell count; Hb: Hemoglobin; Ht: Hematocrit; MCV: Mean corpuscular volume; MCH: Mean corpuscular hemoglobin; MCHC: Mean corpuscular hemoglobin concentration; PLT: Platelet count; TP: Total protein; Alb: Albumin; AST(GOT): Aspartate aminotransferase (glutamic oxaloacetic transaminase); ALT(GPT): Alanine aminotransferase (glutamic pyruvic transaminase); ALP: Alkaline phosphatase; LAP: Leucine aminopeptidase; LD(LDH): Lactate dehydrogenase; $\gamma$-GTP: $\gamma$-glutamyltransferase; TG: Triglyceride; TC: Total cholesterol; HDL-C: High-density lipoprotein cholesterol; LDL-C: Low-density lipoprotein cholesterol; HbA1c: Hemoglobin A1c; FBS: Fasting blood sugar

\section{Acknowledgements}

We would like to thank Editage (www.editage.com) for English language editing.

\section{Authors' contributions}

S.S. designed and performed the experiments, analyzed and interpreted data, and prepared the manuscript. H.O., T.N., D.N., P.D. T.Y., and T.O. performed the experiments. H.K. was responsible for the medical examination of the participants. S.M. and H.N. contributed to the manuscript preparation and to the discussion, and they are the guarantors of this work. All the authors reviewed and approved the final manuscript.

\section{Funding}

This research was supported by the Center of Innovation (COI) Program from Japan Science and Technology Agency (JST). The program is one of the main funding programs under the Center of Innovation Science and Technology based on the Radical Innovation and Entrepreneurship Program (COI STREAM), which was launched in 2013 by the Ministry of Education, Culture, Sports, Science and Technology (MEXT). This study was also supported by the Grant-in-Aid from JSPS KAKENHI (grant no19K20158 to SS), and the Juntendo University Institute of Health and Sports Science \& Medicine.

\section{Availability of data and materials}

The datasets analyzed during the current study are available from the corresponding author on reasonable request.

\section{Declarations}

\section{Ethics approval and consent to participate}

This study was conducted in accordance with the Declaration of Helsinki and was approved by the Ethics Committee for Human Experiments of Juntendo University, Chiba, Japan (Approval Number: 27-52). Written informed consent was obtained from all study participants.

\section{Consent for publication}

Not applicable.

\section{Competing interests}

The authors declare that they have no competing interests.

\section{Author details}

${ }^{1} \mathrm{COI}$ Project Center, Juntendo University, 2-1-1 Hongo, Bunkyo-ku, Tokyo 113-8421, Japan. ${ }^{2}$ School of Health and Sports Science, Juntendo University, 1-1 Hirakagakuendai, Inzai, Chiba 270-1695, Japan. ${ }^{3}$ School of Sport and Health Science, Tokai Gakuen University, 21-233 Nishinohora, Ukigai, Miyoshi, Aichi 470-0207, Japan. ${ }^{4}$ Department of Human Structure \& Function, Tokai University School of Medicine, 143 Shimokasuya, Isehara, Kanagawa 259-1193, Japan. ${ }^{5}$ Ritsumeikan Global Innovation Research Organization, Ritsumeikan University, 1-1-1 Noji-higashi, Kusatsu, Shiga 525-8577, Japan. ${ }^{6}$ Graduate School of Health and Sports Science, Juntendo University, 1-1 Hirakagakuendai, Inzai, Chiba 270-1695, Japan. ${ }^{7}$ Faculty of Sports and Health Sciences, Japan Women's College of Physical Education, 8-19-1, Kitakarasuyama, Setagaya-ku, Tokyo 157-8565, Japan. ${ }^{8}$ Department of Internal Medicine, Mito Kyodo General Hospital, University of Tsukuba, 3-2-7
Miyamachi, Mito, Ibaraki 310-0015, Japan. ${ }^{9}$ Institute of Health and Sports Science \& Medicine, Juntendo University, 1-1 Hirakagakuendai, Inzai, Chiba 270-1695, Japan.

Received: 17 December 2020 Accepted: 30 July 2021

Published online: 18 August 2021

\section{References}

1. Wang DXM, Yao J, Zirek Y, Reijnierse EM, Maier AB. Muscle mass, strength, and physical performance predicting activities of daily living: ameta-analysis. J Cachexia Sarcopenia Muscle. 2020;11(1):3-25.

2. Holloszy JO. Exercise-induced increase in muscle insulin sensitivity. J Appl Physiol. 2005;99(1):338-43.

3. Iannuzzi-Sucich M, Prestwood KM, Kenny AM. Prevalence of sarcopenia andpredictors of skeletal muscle mass in healthy, older men and women. J GerontolA Biol Sci Med Sci. 2002;57(12):M772-777.

4. Janssen I, Heymsfield SB, Wang ZM, Ross R. Skeletal muscle mass anddistribution in 468 men and women aged 18-88 yr. J Appl Physiol. 2000;89(1):81-8.

5. Ida S, Kaneko R, Imataka K, Murata K. Association between sarcopenia and renal function in patients with diabetes: a systematic review and metaanalysis. J Diabetes Res. 2019;2019:1365189.

6. Ishii S, Tanaka T, Akishita M, Ouchi Y, Tuji T, lijima K. Kashiwa studyi: Metabolic syndrome, sarcopenia and role of sex and age: crosssectionalanalysis of Kashiwa cohort study. PLoS One. 2014;9(11):e112718.

7. Jones SE, Maddocks M, Kon SS, Canavan JL, Nolan CM, Clark AL, Polkey MI, Man WD. Sarcopenia in COPD: prevalence, clinical correlates and response topulmonary rehabilitation. Thorax. 2015;70(3):213-8.

8. Sanada K, lemitsu M, Murakami H, Gando Y, Kawano H, Kawakami R, Tabatal I, Miyachi M. Adverse effects of coexistence of sarcopenia and metabolicsyndrome in Japanese women. Eur J Clin Nutr. 2012;66(10):1093-8.

9. Yeung SSY, Reijnierse EM, Pham VK, Trappenburg MC, Lim WK, Meskers CGM, Maier AB. Sarcopenia and its association with falls and fractures in olderadults: a systematic review and meta-analysis. J Cachexia Sarcopenia Muscle. 2019;10(3):485-500.

10. Yoshimura N, Muraki S, Oka H, lidaka T, Kodama R, Kawaguchi H, Nakamura K, Tanaka S, Akune T. Is osteoporosis a predictor for future sarcopenia or vice-versa? Four-year observations between the second and third ROAD study surveys. OsteoporosInt. 2017;28(1):189-99.

11. Yuki A, Ando F, Otsuka R, Shimokata H. Sarcopenia based on the Asian Working Group for Sarcopenia criteria and all-cause mortality risk in older Japanese adults. Geriatr Gerontol Int. 2017;17(10):1642-7.

12. Chen LK, Woo J, Assantachai P, Auyeung TW, Chou MY, lijima K, Jang HC, Kang L, Kim M, Kim S, et al. Asian Working Group for Sarcopenia: 2019 Consensus Update on Sarcopenia Diagnosis and Treatment. J Am Med Dir Assoc. 2020;21(3):300-7 e302.

13. Cruz-Jentoft AJ, Bahat G, Bauer J, Boirie Y, Bruyere O, Cederholm T, Cooper C, Landi F, Rolland Y, Sayer AA, et al. Sarcopenia: revised Europeanconsensus on definition and diagnosis. Age Ageing. 2019;48(1):16-31.

14. Borst SE. Interventions for sarcopenia and muscle weakness in olderpeople. Age Ageing. 2004;33(6):548-55.

15. Yoshimura Y, Wakabayashi H, Yamada M, Kim H, Harada A, Arai H. Interventions for treating sarcopenia: a systematic review and meta-analysis of randomized controlled studies. J Am Med Dir Assoc. 2017;18(6):553 e551553 e516.

16. Ozaki H, Sawada S, Osawa T, Natsume T, Yoshihara T, Deng P, Machida S, Naito $\mathrm{H}$. Muscle size and strength of the lower body in supervised and in combined supervised and unsupervised low-load resistance training. J Sports Sci Med. 2020;19(4):721.

17. Biolo G, Ciocchi B, Stulle M, Bosutti A, Barazzoni R, Zanetti M, Antonione R, Lebenstedt $M$, Platen $P$, Heer $M$, et al. Calorie restriction accelerates the catabolism of lean body mass during 2 wk of bed rest. Am J Clin Nutr. 2007;86(2):366-72

18. Yamada M, Kimura Y, Ishiyama D, Nishio N, Otobe Y, Tanaka T, Ohji S, Koyama S, Sato A, Suzuki M, et al. Synergistic effect of bodyweight resistance exercise and protein supplementation on skeletal muscle in sarcopenic or dynapenic older adults. Geriatr Gerontol Int. 2019;19(5):429-37.

19. Arai H, Yamamoto A, Matsuzawa Y, Saito Y, Yamada N, Oikawa S, Mabuchi H, Teramoto T, Sasaki J, Nakaya N, et al. Prevalence of metabolic syndrome in the general Japanese population in 2000. J Atheroscler Thromb. 2006; 13(4):202-8 
20. Pellicano R, Oliaro E, Fagoonee S, Astegiano M, Berrutti M, Saracco G, Smedile A, Repici A, Leone N, Castelli A, et al. Clinical and biochemical parameters related to cardiovascular disease after Helicobacter pylori eradication. Int Angiol. 2009;28(6):469-73.

21. Yoshihara T, Ozaki H, Nakagata T, Natsume T, Kitada T, Ishihara Y, Sawada S, Ishibashi M, Kobayashi H, Machida S, et al. Association between locomotive syndrome and blood parameters in Japanese middle-aged and elderly individuals: a cross-sectional study. BMC Musculoskelet Disord. 2019;20(1):104

22. Ministry of Health, Labour and Welfare: Comprehensive Survey of Living Conditions. 2016. https://www.mhlw.go.jp/english/database/db-hss/cslcreport2016.html. Accessed 14 June 2021.

23. Leon AS, Gaskill SE, Rice T, Bergeron J, Gagnon J, Rao DC, Skinner JS, Wilmore $\mathrm{H}$, Bouchard C. Variability in the response of HDL cholesterol to exercise training in the HERITAGE Family Study. Int J Sports Med. 2002;23(1):1-9.

24. Schalk BW, Deeg DJ, Penninx BW, Bouter LM, Visser M. Serum albumin and muscle strength: a longitudinal study in older men and women. J Am Geriatr Soc. 2005;53(8):1331-8.

25. Maeda K, Akagi J. Muscle mass loss is a potential predictor of 90daymortality in older adults with aspiration pneumonia. J Am Geriatr Soc. 2017;65(1):e18-22.

26. Ng TP, Niti M, Feng L, Kua EH, Yap KB. Albumin, apolipoproteinE-epsilon4 and cognitive decline in community-dwelling Chinese older adults. JAm Geriatr Soc. 2009;57(1):101-6.

27. Taniquchi Y, Kitamura A, Kaito S, Yokoyama Y, Yokota I, Shinozaki T, Seino S, Murayama H, Matsuyama Y, lkeuchi T, et al. Albumin and hemoglobin trajectories and incident disabling dementia in community-dwelling older Japanese. Dement Geriatr Cogn Disord. 2019;47(4-6):233-42.

28. Taniguchi Y, Shinkai S, Nishi M, Murayama H, Nofuji Y, Yoshida H, Fujiwara Y. Nutritional biomarkers and subsequent cognitive decline among community-dwelling older Japanese: a prospective study. J Gerontol A Biol Sci Med Sci. 2014;69(10):1276-83.

29. Snyder CK, Lapidus JA, Cawthon PM, Dam TT, Sakai LY, Marshall LM, Osteoporotic Fractures in Men Research G. Serum albumin in relation to change in muscle mass, muscle strength, and muscle power in older men. Am Geriatr Soc. 2012;60(9):1663-72.

30. Visser M, Kritchevsky SB, Newman AB, Goodpaster BH, Tylavsky FA, Nevitt $M C$, Harris TB. Lower serum albumin concentration and change in muscle mass: the Health, Aging and Body Composition Study. Am J Clin Nutr. 2005; 82(3):531-7.

31. Uemura K, Doi T, Lee S, Shimada H. Sarcopenia and Low Serum Albumin Level Synergistically Increase the Risk of Incident Disability in Older Adults. J Am Med Dir Assoc. 2019;20(1):90-3.

32. Binder EF, Yarasheski KE, Steger-May K, Sinacore DR, Brown M, Schechtman $\mathrm{KB}$, Holloszy JO. Effects of progressive resistance training on body composition in frail older adults: results of a randomized, controlled trial. $J$ Gerontol ABiol Sci Med Sci. 2005:60(11):1425-31.

33. Kim HK, Suzuki T, Saito K, Yoshida H, Kobayashi H, Kato H, Katayama M. Effects of exercise and amino acid supplementation on body composition and physical function in community-dwelling elderly Japanese sarcopenic women: a randomized controlled trial. J Am Geriatr Soc 2012:60(1):16-23.

\section{Publisher's Note}

Springer Nature remains neutral with regard to jurisdictional claims in published maps and institutional affiliations.

Ready to submit your research? Choose BMC and benefit from:

- fast, convenient online submission

- thorough peer review by experienced researchers in your field

- rapid publication on acceptance

- support for research data, including large and complex data types

- gold Open Access which fosters wider collaboration and increased citations

- maximum visibility for your research: over $100 \mathrm{M}$ website views per year

At $\mathrm{BMC}$, research is always in progress.

Learn more biomedcentral.com/submissions 